\title{
Review
}

\section{Current Evidence in Haemodiafiltration}

\author{
Francesco Locatelli Leano Violo Selena Longhi Lucia Del Vecchio
}

Department of Nephrology and Dialysis, Alessandro Manzoni Hospital, Lecco, Italy

\section{Key Words}

Chronic kidney disease · Dialysis · Haemodiafiltration ·

High-flux dialysis · Anaemia · Phosphate · Cardiovascular stability

\begin{abstract}
Background: Standard low-flux haemodialysis (HD) is not very efficacious, and patient morbidity and mortality rates are still very high. According to the initial study design, the MPO study reported that high-flux HD (hf-HD) showed a significant $37 \%$ relative risk reduction of mortality in patients with serum albumin $\leq 4 \mathrm{~g} / \mathrm{dl}$; online haemodiafiltration (HDF) is considered the most efficient technique of using high-flux membranes, as clearances of small solutes, like urea, are higher than in haemofiltration and clearances of middle solutes, like $\beta_{2}$-microglobulin, are higher than in hf-HD. Summary: Three randomized trials have recently been published analysing the effect of online HDF on mortality. Two trials were unable to demonstrate a positive effect of HDF on survival, while 1 showed a significantly better survival in patients randomized to HDF in comparison to those randomized to hf-HD. It is intriguing that post hoc analyses of these 3 studies showed that the patients randomized to online HDF who received the highest convection volumes had a lower risk of mortality and cardiovascular events than those randomized to HD. Four very recently published meta-analyses have shown inconsistent results concerning the effect of convective treatments in improving patient general and cardiovascular survival, while they have consistently shown a significant reduction of the intradialytic symptomatic hypotension in patients treated
\end{abstract}

\section{KARGER 125\%}

(c) 2015 S. Karger AG, Basel

0253-5068/15/0405-0024\$39.50/0

E-Mail karger@karger.com

www.karger.com/bpu
Francesco Locatelli

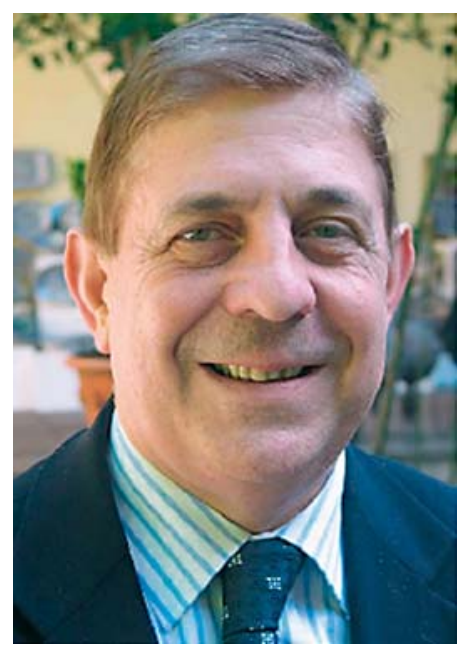

with convective techniques in comparison with those treated with prevalent diffusive ones. Key Messages: The results of the randomized trials on the effect of HDF in improving patient survival are inconclusive. Moreover, trials specifically designed for testing the effect of increased convection of online HDF on patient survival and morbidity in comparison to patients treated with hf-HD are still awaited.

(c) 2015 S. Karger AG, Basel

\section{Introduction}

The aim of haemodialysis (HD) is to control fluid overload, correct electrolyte imbalance and metabolic acidosis, and remove solutes that are normally excreted by
Prof. Francesco Locatelli

Department of Nephrology and Dialysis Alessandro Manzoni Hospital

Via dell'Eremo 9/11, IT-23900 Lecco (Italy)

E-Mail f.locatelli@ospedale.lecco.it 
the kidneys. Unfortunately, standard low-flux HD is not very efficacious compared to healthy kidneys, and patient morbidity and mortality rates are still very high. Highflux HD (hf-HD) is an alternative efficient dialysis technique, which was introduced many years ago on the hypothesis that the high morbidity and mortality rates of low-flux HD were partially due to inadequate removal of middle molecule solutes [1]. High-flux membranes remove solutes of higher molecular weight, such as $\beta_{2^{-}}$ microglobulin $(11.8 \mathrm{kDa})$ and show high biocompatibility, thus reducing the activation of several cellular mechanisms and biological systems that cause chronic inflammation and oxidative stress [2].

At primary analysis, the HEMO study [3] showed that hf-HD was associated with a non-significant mortality relative risk (RR) reduction of $8 \%$ in comparison with low-flux HD. However, a secondary analysis of the patients who were on renal replacement therapy for $>3.7$ years showed a significantly better survival in the highflux group, with a $32 \%$ reduction of the mortality RR [4].

The Membrane Permeability Outcome (MPO) study [5] is a study specifically designed to include a sicker patient population that could take more advantage from hf$\mathrm{HD}$, in order to provide sufficient statistical power. Seven hundred and thirty-eight chronic kidney disease stage 5 dialysis patients were enrolled (567 of them had serum albumin $\leq 4 \mathrm{~g} / \mathrm{dl}$, and 171 had serum albumin $>4 \mathrm{~g} / \mathrm{dl}$ ) and were separately randomized to not jeopardize the original study design. No significant effect of membrane permeability on survival was found in the population as a whole. However, according to the initial study design, hf-HD showed a significant $37 \%$ RR reduction of mortality in patients with serum albumin $\leq 4 \mathrm{~g} / \mathrm{dl}$. A post hoc analysis found a higher survival rate in the diabetic population as a whole treated with the high-flux mode, with an adjusted RR reduction of $38 \%$. The causal relation between treatment with hf-HD and survival could lie in the removal capacity of high-flux membranes for $\beta_{2^{-}}$ microglobulin (an acknowledged surrogate of the middle molecules) positively affecting serum levels in the long term, which in turn are related to mortality [6]. However, the interpretation of these findings could be related to many factors, including a better volume control, which is easier with this dialysis technique.

The European Renal Best Practice Advisory Board considered that the MPO study provides sufficient evidence to upgrade the strength of the guidance to a level $1 \mathrm{~A}$ (strong recommendation, based on high-quality evidence) that hf-HD should be used in the case of high-risk patients (comparable to the low-albumin group of the
MPO study). Given the substantial improvement in an intermediate marker ( $\beta_{2}$-microglobulin) in the high-flux group of the MPO study, the European Renal Best Practice Advisory Board considers that synthetic high-flux membranes should be recommended even in low-risk patients (level 2b: weak recommendation, low-quality evidence) [7].

Online haemodiafiltration (HDF) is considered the most efficient technique of using high-flux membranes as clearances of small solutes like urea are higher than in haemofiltration (HF) and clearances of middle solutes like $\beta_{2}$-microglobulin are higher than in hf-HD.

In a prospective, randomized, multicentre trial, Locatelli et al. [8] compared biocompatible and non-biocompatible membranes, convective and diffusive treatment modalities (cuprophane HD, low-flux polysulphone HD, high-flux polysulphone $\mathrm{HD}$, high-flux polysulphone HDF) in 380 patients followed for 24 months. No significant differences in treatment tolerance and cardiovascular stability were shown between the four treatment groups. However, the incidence of intradialytic hypotension in the population as a whole was much lower than expected. Moreover, no difference of mortality between low-flux and high-flux groups was found although the study was not designed for this end point.

As far as a decrease in predialysis phosphate levels is concerned, data in the literature are inconsistent [9-12]. The same holds true for anaemia $[13,14]$.

Serum $\beta_{2}$-microglobulin concentration is strongly associated with mortality risk in dialysis patients. In a large observational study comparing convective with diffusive treatments, a $10 \%$ non-significant better survival was associated with convective treatments [15]. Of note, a $42 \%$ lower RR for surgical intervention for carpal tunnel syndrome was reported in patients in convective treatments.

Wizemann et al. [16] performed a 24-month controlled prospective study in which 44 chronic dialysis patients were randomized to either low-flux HD or online HDF. There were neither differences in morbidity, blood pressure, dialysis-associated hypotensive episodes, haematocrit or erythropoietin dose between the groups, nor any differences in body weight and nutrition parameters.

Cardiovascular instability is the most frequent clinical problem on dialysis. The importance of preventing intradialytic hypotension is mainly related to the reduction of organ ischaemia and the need of achieving the patient dry body weight, thus better controlling hypertension that in HD patients is mainly dependent on fluid overload. A better haemodynamic stability of online HDF was reported in a prospective, randomized trial by Lin et al. [17]. 
Episodes of symptomatic hypotension and mean saline infusion volumes during treatments were significantly reduced when frequencies of online HDF were increased. Of interest, the authors reported a higher predialysis plasma sodium concentration $(2.3 \mathrm{mEq} / \mathrm{l})$ in patients with higher frequency of online HDF, thus suggesting reduced sodium removal, possibly at least partially responsible for the better cardiovascular stability. The same holds true for the results of the study by Maduell et al. [18].

According to the original observation by Maggiore et al. [19] that dialysate temperature set at about $35^{\circ} \mathrm{C}$ affords a better haemodynamic stability than the standard dialysate temperature of $37-38^{\circ} \mathrm{C}$, an alternative hypothesis to explain the reduction of hypotension episodes during online HDF is suggested by Donauer et al. [20], who identified blood cooling as the main blood pressure-stabilizing factor in online HDF. During online HDF, an enhanced energy loss within the extracorporeal system occurred, despite identical temperature settings for dialysate and substitution fluids. As a result, the blood returning to the patient was cooler during online HDF than during HD. Moreover, the mean blood temperature was lower in online HDF, even in the patient's circulation, and blood volume was significantly more reduced. The incidence of symptomatic hypotension was similar to that of online HDF by using cooler temperature-controlled HD.

In an Italian prospective multicentre study [21], 146 long-term dialysis patients from 27 Italian dialysis centres were randomly assigned to standard low-flux HD ( $\mathrm{n}=$ $70)$, online predilution HF $(\mathrm{n}=36)$ or online predilution HDF $(n=40)$ and followed up for a median of 1.5 years. The primary end point was the frequency of intradialytic symptomatic hypotension. Compared with a run-in period, the frequency of sessions with intradialytic symptomatic hypotension during the evaluation period increased for HD (7.1-7.9\%) and decreased for both HF (9.8-8.0\%) and HDF (10.6-5.2\%; $\mathrm{p}<0.001)$. The beneficial effect of a $54 \%$ reduction of intradialytic symptomatic hypotension in HDF should be balanced with a mean increase in predialysis systolic blood pressure of $4.2 \mathrm{~mm}$ Hg. The ESHOL trial [22] confirmed the results of the Italian trial in reducing the frequency of intradialytic hypotension.

In the Convective Transport Study (CONTRAST) [23], 714 prevalent HD patients were randomly assigned to undergo either online HDF (postdilution, target convection volume 6 litres/ $h ; n=358$ ) or low-flux HD ( $n=$ 356). The primary outcome was all-cause mortality. The main secondary end point was the composite of fatal and non-fatal major cardiovascular events. After a mean follow-up of 3.03 years, the incidence of all-cause mortality was not affected by treatment assignment. However, subgroup analysis suggests benefit among patients treated with high convection volumes ( $>20$ litres/treatment) on all-cause mortality (hazard rate $0.57 ; \mathrm{p}<0.016$ ).

Another prospective randomized, controlled trial, the Turkish HDF Study [24], compared postdilution online HDF and hf-HD regarding morbidity and mortality. Seven hundred and eighty-two HD patients were enrolled and randomly assigned at a 1:1 ratio to either postdilution online HDF or hf-HD. The follow-up period was 2 years. The primary outcome was composite of death from any cause and non-fatal cardiovascular events. The major secondary outcomes were cardiovascular and overall mortality, intradialytic complications, hospitalization rate, changes in laboratory parameters, and medications. The composite end point of death from any cause and nonfatal cardiovascular events was not different between postdilution online HDF and hf-HD. However, HDF treatment with substitution volume $>17.4$ litres was associated with a $46 \% R R$ reduction for overall mortality $(R R=0.54$; $\mathrm{p}=0.02)$ and a $71 \% \mathrm{RR}$ reduction for cardiovascular mortality $(\mathrm{RR}=0.29 ; \mathrm{p}=0.003)$ compared to HD [23].

The ESHOL trial is the first randomized study showing a significant advantage for online HDF in all-cause mortality, stroke mortality and infection-related mortality [22]. Interestingly, the ESHOL trial had the highest achieved convection volumes (22.9-23.9 litres/HD session). However, the solidity of the data depends on the quality of randomization. Unfortunately, the patients randomized to the online HDF in the ESHOL trial were younger, more often male, without diabetes, using in a higher percentage a fistula and fewer catheters, and had a lower comorbidity index [25].

However, it is intriguing that post hoc analyses of the 3 studies showed that patients under online HDF who received the highest convection volumes were associated with a lower mortality and cardiovascular events than those randomized to HD [22-24], thus supporting the findings of the DOPPS study [26].

Unfortunately the majority of the patients in these trials [22-24] did not reach the target exchange volume. It is very likely that the exchange volume was related to the flow of vascular access, likely related to better vessels, thus possibly affecting also patient survival. Moreover, in the ESHOL study [22], exclusion occurred if the preset $18 \mathrm{li}$ tres were not reached. Thus, a selection bias could be a possible explanation for the results of the post hoc analyses of these trials, since the possibility that larger reinfu- 
Table 1. Randomized clinical studies evaluating the role of HDF on patient mortality

\begin{tabular}{|c|c|c|c|c|c|c|}
\hline Reference & Design & Treatments & Patients & $\begin{array}{l}\text { Sample } \\
\text { size }\end{array}$ & $\begin{array}{l}\text { Relative risk } \\
\text { reduction, \% }\end{array}$ & $\begin{array}{l}\mathrm{p} \\
\text { value }\end{array}$ \\
\hline \multirow[t]{3}{*}{ Locatelli et al. [8], 1996} & \multirow[t]{3}{*}{ randomized, prospective } & Cuprophane HD & 132 & \multirow[t]{3}{*}{380} & & \multirow[t]{3}{*}{ n.s. } \\
\hline & & High-flux HD & 51 & & & \\
\hline & & HDF & 50 & & & \\
\hline $\begin{array}{l}\text { Wizemann et al. [16], } \\
2000\end{array}$ & randomized, prospective & $\mathrm{HDF}$ & 23 & 44 & & n.s. \\
\hline \multirow[t]{2}{*}{ Schiffl [31], 2007} & \multirow{2}{*}{$\begin{array}{l}\text { randomized, crossover, } \\
\text { prospective }\end{array}$} & High-flux HD & 76 & \multirow[t]{2}{*}{76} & \multirow[t]{2}{*}{ no difference } & \multirow[t]{2}{*}{ n.s. } \\
\hline & & $\mathrm{HDF}$ & 76 & & & \\
\hline \multirow[t]{3}{*}{ Locatelli et al. [21], 2010} & randomized, prospective & Low-flux HD & 70 & \multirow[t]{3}{*}{146} & & \multirow[t]{3}{*}{ n.s. } \\
\hline & & Online HF & 36 & & & \\
\hline & & Online HDF & 40 & & & \\
\hline $\begin{array}{l}\text { Grootemann et al. [24], } \\
2012\end{array}$ & randomized, prospective & Low-flux HD & & 714 & 9 & n.s. \\
\hline \multirow{4}{*}{$\begin{array}{l}\text { Ok et al. [23], } \\
2013\end{array}$} & \multirow[t]{2}{*}{ randomized, prospective } & High-flux HD & 391 & \multirow[t]{2}{*}{782} & & \multirow[t]{2}{*}{ n.s. } \\
\hline & & Online HDF & 391 & & & \\
\hline & \multirow{2}{*}{$\begin{array}{l}\text { adjusted Cox regression } \\
\text { analysis, secondary } \\
\text { analysis }\end{array}$} & High-flux HD & 391 & \multirow[t]{2}{*}{782} & \multirow[t]{2}{*}{46} & \multirow[t]{2}{*}{0.02} \\
\hline & & Online HDF & 391 & & & \\
\hline \multirow{2}{*}{ Maduell et al. [22], 2013} & \multirow{2}{*}{ randomized, prospective } & $\begin{array}{l}\text { (substitution volume }>17.4 \text { litres) } \\
\text { High-flux HD }\end{array}$ & 450 & 906 & 30 & 0.01 \\
\hline & & Online HDF & 456 & & & \\
\hline
\end{tabular}

Table 2. Randomized clinical studies evaluating the role of HDF on dialysis tolerance

\begin{tabular}{|c|c|c|c|c|c|c|}
\hline \multirow[t]{4}{*}{ Locatelli et al. [8], 1996} & \multirow[t]{4}{*}{ randomized, prospective } & Cuprophane HD & 132 & \multirow[t]{4}{*}{380} & & \multirow[t]{4}{*}{ n.s. } \\
\hline & & Low-flux HD & 147 & & & \\
\hline & & High-flux HD & 51 & & & \\
\hline & & $\mathrm{HDF}$ & 50 & & & \\
\hline \multirow[t]{2}{*}{ Schiffl [31], 2007} & \multirow{2}{*}{$\begin{array}{l}\text { randomized, crossover, prospective, } \\
\text { secondary analysis }\end{array}$} & High-flux HD & 76 & \multirow[t]{2}{*}{152} & \multirow[t]{2}{*}{63.6} & \multirow[t]{2}{*}{$<0.05$} \\
\hline & & $\mathrm{HDF}$ & 76 & & & \\
\hline \multirow[t]{3}{*}{ Locatelli et al. [21], 2010} & \multirow[t]{3}{*}{ randomized, prospective } & Low-flux HD & 70 & \multirow[t]{3}{*}{146} & \multirow[t]{3}{*}{50} & \multirow[t]{3}{*}{0.001} \\
\hline & & Online HF & 36 & & & \\
\hline & & Online HDF & 40 & & & \\
\hline Maduell et al. [22], 2013 & $\begin{array}{l}\text { randomized, prospective, secondary } \\
\text { analysis }\end{array}$ & High-flux HD & 450 & 906 & 28 & $<0.001$ \\
\hline
\end{tabular}

sion volumes could be easier in patients with better vascular access and intradialytic cardiovascular stability cannot be ruled out.

The main points of concerns of online HDF have been safety and extra costs in relation to HD and also to hf-HD. Since online HDF is characterized by the infusion of large volumes of replacement fluid into the blood, the question arises whether online HDF may increase the risk of infection. The 3 studies [22-24] were not specifically designed to study safety. However, apparently online HDF was a very safe dialysis technique and the ESHOL trial demonstrated that infection-related mortality declined by $55 \%$ 
[22]. The additional costs of online HDF could mainly be attributed to disposables and a more frequent control for dialysis water purity. However, the costs of disposables should decrease with their larger use, making online HDF economically competitive to hf-HD and also to standard HD.

Another randomized controlled trial, the French Multicenter Trial, compared the effects of high-efficiency online HDF with hf-HD on dialytic tolerance (primary end point) and mortality in dialysis patients aged 65 years or more in a 2-year follow-up period and found no difference between the 2 groups [Canaud B., pers. commun.].

To try to better clarify these aspects, recently 4 metaanalyses have been published [26-29]. The meta-analysis by Wang et al. [26] included 16 studies, 2 of which were crossover (3,220 patients in total). According to the authors, no significant difference was found in the overall risk of mortality and cardiovascular events between patients treated with HF and HDF and HD, despite a numeric relative risk reduction of 15 and $17 \%$, respectively. Of note, a significant reduction of $51 \%$ of intradialytic symptomatic hypotension was found in patients treated with the convective techniques, associated with a significant reduction of $\beta_{2}$-microglobulin predialytic mean plasma levels of $5.96 \mathrm{mg} / \mathrm{l}$, without a significant difference of the clearances of small molecules evaluated as Kt/V of urea. In their meta-analysis, Nistor et al. [27] included 35 randomized trials, of which 17 were crossover $(4,039 \mathrm{pa}-$ tients overall). No significant advantages of convective techniques were shown in comparison to the prevalent diffusive techniques, although a numerical reduction of $13 \%$ was seen. Of note, a $25 \%$ significant reduction of cardiovascular mortality and a significant reduction of $28 \%$ of intradialytic symptomatic hypotension were found in patients treated with convective techniques. No significant advantages in non-fatal cardiovascular events and hospital admission were observed. Susantitaphong et al. [28] included 65 studies in their meta-analysis, 29 of which had a crossover design (12,182 patients overall). They found a significant reduction of 16 and $45 \%$ of intradialytic symptomatic hypotension in patients treated with convective techniques in comparison with the patients treated with prevalent diffusive ones. Mostovaya et al. [29] performed a meta-analysis of 6 randomized controlled trials (296 patients) and found that HDF treatment was related to a decreased risk of mortality (RR: $0.84 ; 95 \%$ CI $0.73-0.96$ ) and cardiovascular death (RR: 0.73 ; 95\% CI 0.57-0.92).

\section{Conclusions}

At present no conclusive data are available concerning the effect of increased convection of online HDF on survival and morbidity in HD patients (table 1).

Convective treatments are also able to facilitate the removal of sodium and water overload, allowing a better intradialytic vascular stability [21]. It is possible that the positive effects of convective treatments are mainly related to better fluid control and less intradialytic organ ischaemia (table 2). It is important to underline that it is very difficult to demonstrate the positive effects of convective treatments in randomized controlled trials, where there is a selection bias of motivated participating centres including doctors, nurses and patients.

The 4 meta-analyses on the topic [26-29] have underlined the methodological limitations of the included trials. Thus, their conclusions should be carefully evaluated. However, all the 4 meta-analyses [26-29] have shown a significant reduction of the intradialytic symptomatic hypotension in patients treated with convective techniques in comparison with the patients treated with prevalent diffusive ones, although the interpretation of these findings is still a matter of discussion. A post hoc analysis of the 3 largest randomized controlled trials suggested an inverse relation between the magnitude of the convection volume and mortality risk.

\section{Disclosure Statement}

The authors have no conflict of interest to declare related to this paper.

\section{References}

Von Albertini B, Miller JH, Gardner PW, et al: High-flux haemodiafiltration: under six hours/week treatment. Trans Am Soc Artif Intern Organs 1984;30:227-231.

-2 Del Vecchio L, Locatelli, F, Carini M: What we know about oxidative stress in patients with chronic kidney disease on dialysis: clinical effects, potential treatment, and prevention. Semin Dial 2011;24:56-64.
Eknoyan G, Beck GJ, Cheung AK, et al: Effect of dialysis dose and membrane flux in maintenance haemodialysis. N Engl J Med 2002; 347:2010-2019.

4 Cheung AK, Levin NW, Greene T, et al: Effects of high-flux haemodialysis on clinical outcomes: results of the HEMO study. J Am Soc Nephrol 2003;14:3251-3263. 
5 Locatelli F, Martin-Malo A, Hannedouche T, et al: Effect of membrane permeability on survival of haemodialysis patients. J Am Soc Nephrol 2009;20:645-654.

6 Cheung AK, Rocco MV, Yan G, et al: Serum beta-2 microglobulin levels predict mortality in dialysis patients: results of the HEMO study. J Am Soc Nephrol 2006;17:546-555.

7 Tattersall J, Martin-Malo A, Pedrini L, et al: EBPG guideline on dialysis strategies. Nephrol Dial Transplant 2007;22:ii5-ii21.

8 Locatelli F, Mastrangelo F, Redaelli B, et al: Effects of different membranes and dialysis technologies on patient treatment tolerance and nutritional parameters. The Italian Cooperative Dialysis Study Group. Kidney Int 1996;50:1293-1302.

-9 Penne EL, van der Weerd NC, van der Dorpel MA, et al: Short-term effects of on-line haemodiafiltration on phosphate control: a result from the randomized controlled Convective Transport Study (CONTRAST). Am J Kidney Dis 2010;55:77-87.

10 Locatelli F, Altieri P, Andrulli S, et al: Phosphate levels in patients treated with low-flux haemodialysis, predilution haemofiltration and haemodiafiltration: post hoc analysis of a multicentre, randomized and controlled trial. Nephrol Dial Transplant 2014;29:1239-1246.

11 Pedrini L, De Cristofaro V, Comelli M, et al: Long-term effects of high-efficiency on-line haemodiafiltration on uraemic toxicity. A multicentre prospective randomized study. Nephrol Dial Transplant 2011;26:2617-2624.

$\checkmark 12$ Movilli E, Camerini C, Gaggia P, et al: Effect of post-dilutional on-line haemodiafiltration on serum calcium, phosphate and parathyroid hormone concentrations in uraemic patients. Nephrol Dial Transplant 2011;26: 4032-4037.

13 Locatelli F, Altieri P, Andrulli S, et al: Predictors of haemoglobin levels and resistance to erythropoiesis-stimulating agents in patients treated with low-flux haemodialysis, haemofiltration and haemodiafiltration: results of a multicenter randomized and controlled trial. Nephrol Dial Transplant 2012;27:3594-3600.
4 Panichi V, Scatena A, Rosati A, et al: Highvolume online haemodiafiltration improves erythropoiesis-stimulating agent (ESA) resistance in comparison with low-flux bicarbonate dialysis: results of the REDERT study. Nephrol Dial Transplant 2015;30:682-689.

15 Locatelli F, Marcelli D, Conte F, et al: Comparison of mortality in ESRD patients on convective and diffusive extracorporeal treatments. The Registro Lombardo Dialisi e Trapianto. Kidney Int 1999;55:286-293.

16 Wizemann V, Lotz C, Techert F, et al: On-line haemodiafiltration versus low-flux haemodialysis: a prospective randomized study. Nephrol Dial Transplant 2000;15(suppl 1): 43-48.

17 Lin CL, Huang CC, Chang CT, et al: Clinical improvement by increased frequency of online haemodiafiltration. Ren Fail 2001;23: 193-206.

18 Maduell F, del Pozo C, Garcia H, et al: Change from conventional haemodiafiltration to online haemodiafiltration. Nephrol Dial Transplant 1999;14:1202-1207.

19 Maggiore Q, Pizzarelli F, Sisca S, et al: Blood temperature and vascular stability during haemodialysis and hemofiltration. Trans Am Soc Artif Intern Organs 1982;28:523-537.

20 Donauer J, Schweiger C, Rumberger B, et al: Reduction of hypotensive side effects during online-haemodiafiltration and low temperature haemodialysis. Nephrol Dial Transplant 2003;18:1616-1622.

21 Locatelli F, Altieri P, Andrulli S, et al: Hemofiltration and haemodiafiltration reduce intradialytic hypotension in ESRD. J Am Soc Nephrol 2010;21:1798-1807.

22 Maduell F, Moreso F, Pons M, et al: High-efficiency postdilution online hemodiafiltration reduces all-cause mortality in hemodialysis patients. J Am Soc Nephrol 2013;24:487498.
23 Ok E, Asci G, Toz H, et al: Mortality and cardiovascular events in online haemodiafiltration (OL-HDF) compared with high-flux dialysis: results from the Turkish OL-HDF. Nephrol Dial Transplant 2013;28:192-202.

24 Grootemann M, Van den Dorpel MA, Bots ML, et al: Effect of online hemodiafiltration on all-cause mortality and cardiovascular outcomes. J Am Soc Nephrol 2012;23:10871096.

25 Locatelli F, Horl WH: A step towards making online hemodiafiltration a gold standard. Nat Rev Nephrol 2013;9:316-318

26 Wang AY, Ninomiya T, Al-Kahwa A, et al: Effect of hemodiafiltration or hemofiltration compared with hemodialysis on mortality and cardiovascular disease in chronic kidney failure: a systematic review and meta-analysis of randomized trials. Am J Kidney Dis 2014; 63:968-978.

27 Nistor I, Palmer SC, Craig JC, et al: Convective versus diffusive dialysis therapies for chronic kidney failure: an updated systematic review of randomized controlled trials. Am J Kidney Dis 2014;63:654-667.

28 Susantitaphong P, Siribamrungwong M, Jaber BL, et al: Convective therapies versus lowflux hemodialysis for chronic kidney failure: a meta-analysis of randomized controlled trials. Nephrol Dial Transplant 2013;28:28592874.

29 Mostovaya IM, Blankestijn PJ, Bots ML, et al: Clinical evidence on hemodiafiltration: a systematic review and a meta-analysis. Semin Dial 2014;27:119-127.

-30 Altieri P, Sorba G, Bolasco P, et al; Sardinian Study Group on Hemofiltration On-Line: Comparison between hemofiltration and hemodiafiltration in a long-term prospective cross-over study. J Nephrol 2004;17:414422.

-31 Schiffl H: Prospective randomized cross-over long-term comparison of online haemodiafiltration and ultrapure high-flux haemodialysis. Eur J Med Res 2007;12:26-33. 